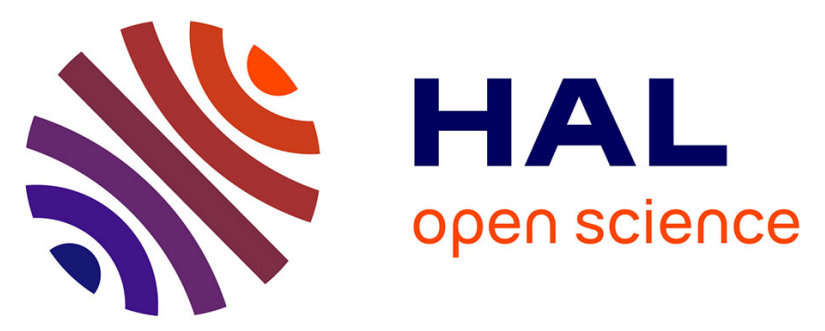

\title{
Impact of early complications on outcomes in patients with implantable cardioverter-defibrillator for primary prevention
}

Maria Soledad Ascoeta, Eloi Marijon, Pascal Defaye, Didier Klug, Frankie Beganton, Marie-Cécile Perier, Daniel Gras, Vincent Algalarrondo, Jean-Claude Deharo, Christophe Leclercq, et al.

\section{To cite this version:}

Maria Soledad Ascoeta, Eloi Marijon, Pascal Defaye, Didier Klug, Frankie Beganton, et al.. Impact of early complications on outcomes in patients with implantable cardioverter-defibrillator for primary prevention. Heart Rhythm, 2016, 13 (5), pp.1045-1051. 10.1016/j.hrthm.2015.12.046 . hal-01272165

HAL Id: hal-01272165

https://hal-univ-rennes1.archives-ouvertes.fr/hal-01272165

Submitted on 10 Feb 2016

HAL is a multi-disciplinary open access archive for the deposit and dissemination of scientific research documents, whether they are published or not. The documents may come from teaching and research institutions in France or abroad, or from public or private research centers.
L'archive ouverte pluridisciplinaire HAL, est destinée au dépôt et à la diffusion de documents scientifiques de niveau recherche, publiés ou non, émanant des établissements d'enseignement et de recherche français ou étrangers, des laboratoires publics ou privés. 
Impact of early complications on outcomes in patients with implantable cardioverterdefibrillator for primary prevention

Short title: Incidence and impact of early complications of ICD

Maria Soledad Ascoeta, MD, ${ }^{1}$ Eloi Marijon, MD, PhD, ${ }^{2}$ Pascal Defaye, MD, ${ }^{3}$

Didier Klug, MD, PhD, ${ }^{4}$ Frankie Beganton, MS, ${ }^{5}$ Marie-Cécile Perier,MPH, ${ }^{5}$

Daniel Gras, $\mathrm{MD},{ }^{6}$ Vincent Algalarrondo, MD, $\mathrm{PhD},{ }^{7}$ Jean-Claude Deharo, $\mathrm{MD}$, $\mathrm{PhD},{ }^{8}$ Christophe Leclercq, MD, PhD, ${ }^{9}$ Laurent Fauchier, MD, $\mathrm{PhD},{ }^{10}$ Dominique Babuty, MD, PhD, ${ }^{10}$ Pierre Bordachar, MD, PhD, ${ }^{11}$ Nicolas Sadoul, MD, PhD, ${ }^{12}$ Serge Boveda, MD, ${ }^{13}$ Olivier Piot, MD, ${ }^{1}$ on behalf of the DAI-PP Investigatorst

${ }^{1}$ Centre Cardiologique du Nord, Saint Denis, France;

${ }^{2}$ European Georges Pompidou Hospital and Paris Descartes University, Paris, France;

${ }^{3} \mathrm{CHU}$ Michallon, Grenoble, France;

${ }^{4}$ CHRU Lille, Lille, France;

${ }^{5}$ Paris Cardiovascular Research Center, Inserm U970, Paris, France;

${ }^{6}$ Nouvelles Cliniques Nantaises, Nantes, France;

${ }^{7} \mathrm{CHU}$ Antoine Béclère, Clamart, France;

${ }^{8} \mathrm{CHU}$ La Timone, Marseille, France;

${ }^{9} \mathrm{CHU}$ Pontchaillou, Rennes, France;

${ }^{10} \mathrm{CHU}$ Trousseau, Tours, France;

${ }^{11}$ CHU Haut Lévêque, Bordeaux, France;

${ }^{12}$ CHU Brabois, Nancy, France

${ }^{13}$ Clinique Pasteur, Toulouse, France; 


\section{Corresponding author:}

Olivier Piot, MD

0033149334182 o.piot@ccncardio.com

Cardiologie 2 - Rythmologie, Centre Cardiologique du Nord, 32-36 rue des Moulins

Gémeaux 93207 Saint Denis cedex

\section{Disclosures}

Dr. Klug has received consultant fees from St. Jude Medical, Medtronic, Sorin Group, Boston Scientific, and Biotronik. Dr. Babuty has received travel support and clinical study support from Biotronik, Boston Scientific, Medtronic, St. Jude Medical, and Sorin Group. Dr. Sadoul has received personal fees from Biotronik, Boston Scientific, Medtronic, Sorin Group, and St. Jude Medical. Dr. Boveda has received consulting fees from Medtronic, Boston Scientific, and Sorin Group. Dr. Piot has received consulting honoraria from Medtronic and St. Jude Medical and researchgrants from Medtronic and Boston Scientific. All other authors have reported that they have no relationships relevant to the contents of this paper to disclose.

ABBREVIATIONS AF, atrial fibrillation; $\mathbf{C l}=$ confidence interval; $\mathbf{C R T}=$ cardiac resynchronization therapy; DAI-PP = Défibrillateur Automatique Implantable-Prévention Primaire; EC = early complication; EF = ejection fraction; $\mathbf{I C D}=$ implantable cardioverterdebrillator; NYHA = New York Heart Association; $\mathbf{O R}=$ odds ratio.

Keywords: Defibrillator; Complication; Primary prevention; Mortality; Morbidity; Sudden death. 
Abstract: BACKGROUND The life-saving benefit of implantable cardioverterdefibrillators (ICD) has been demonstrated. Their use has increased considerably in the past decade, but related complications have become a major concern.

OBJECTIVE We assessed the incidence and effect on outcomes of early $(\leq 30$ days) complications after ICD implantation for primary prevention in a large French population.

METHODS We analyzed data from 5539 patients from the multicenter French DAI-PP registry (2002-2012) who had coronary artery disease or dilated cardiomyopathy and were implanted with an ICD for primary prevention. RESULTS Overall, early complications occurred in 707 (13.5\%) patients, mainly related to lead dislodgement or hematoma (57\%). Independent factors associated with occurrence of early complications were severe renal impairment (odds ratio [OR] 1.66, 95\% confidence interval [CI] 1.17-2.37, $\mathrm{P}=.02$ ), age $>=75$ years (OR 1.01, 95\% CI 1.00-1.02, $\mathrm{P}=.03$ ), cardiac resynchronization therapy (OR $1.58,95 \%$ CI 1.16-2.17, $\mathrm{P}=.01$ ), and anticoagulant therapy (OR $1.28,95 \%$ CI 1.02-1.61, P = .03). During a mean \pm SD follow-up of $3.1 \pm 2.3$ years, $824(15.8 \%)$ patients experienced $\geq 1$ late complication ( $>30$ days), and $782(14.9 \%)$ patients died. After adjustment, early complications remained associated with occurrence of late complications (OR 2.15, 95\% CI 1.73-2.66, $\mathrm{P}<.0001$ ) and mortality (OR 1.70, 95\% CI 1.34-2.17, P =.003).

CONCLUSION Early complications are common after ICD implantation for primary prevention, occurring in 1 in 7 patients, and are associated with an increased risk of late complications and overall mortality. Further studies are needed to investigate the underlying mechanisms of such associations. 


\section{Introduction}

The beneficial effect of an implantable cardiac-defibrillator (ICD) on primary prevention of sudden cardiac death in patients with a severe left ventricular systolic dysfunction has been well demonstrated ${ }^{1-5}$. However, ICD implantation has the potential for complications, with a higher rate observed in daily clinical practice than is usually reported in randomized trials ${ }^{6}$. To date, the extent to which early complications (ECs) are associated with morbidity and mortality in daily practice has been addressed only in limited populations ${ }^{7,8,9}$.

In this analysis, we aimed to assess the incidence and prognosis of ECs after implantation of ICDs for primary prevention in a large French population from the Défibrillateur Automatique Implantable-Prévention Primaire (DAI-PP; NCT\#01992458) registry.

\section{Methods}

\section{Population}

The DAI-PP registry enrolled all patients with coronary artery disease or dilated cardiomyopathy implanted with an ICD for primary prevention between 2002 and 2012 in 12 French centers. The registry was funded by private (Association de Rythmologie Toulousaine - Clinique Pasteur) and public sources, including the French Institute of Health and Medical Research (INSERM) and the French Society of Cardiology. The overall DAI-PP registry was coordinated by the Clinique Pasteur, Toulouse and the Paris Cardiovascular Research Centre, European Georges Pompidou Hospital, Paris (See supplementary material). The DAI-PP registry complied with the principles outlined in the Declaration of Helsinki. The data file was approved and authorized by the French data protection committee (Commission Nationale Informatique et Liberté, CNIL \#913203) and by the local ethics committee of each hospital.

To be included in the registry, ICD recipients had to be at least 18 years old at the time of the implant procedure. All patients with ischemic or non-ischemic cardiomyopathy who were implanted with an ICD (single, double, or triple chamber) in the setting of primary 
prevention were enrolled in the DAI-PP follow-up program. Indications for ICD were as established by the treating physicians, but to meet the 'primary prevention' requirement there had to be no history of sudden cardiac arrest or documented ventricular tachycardia/fibrillation. Ischemic cardiomyopathy was defined as the presence of myocardial dysfunction resulting from previous myocardial infarction or history of coronary artery disease with or without revascularization (angioplasty or bypass surgery at least 3 months prior to implant). All other patients were classified as having non-ischemic cardiomyopathy.

Patients who had received ICD for secondary prevention, and primary prevention patients without structural heart disease (e.g. Brugada syndrome, long QT syndrome) or with structural heart disease other than ischemic or non-ischemic cardiomyopathy (e.g. valvular heart disease, hypertrophic cardiomyopathy, non-compaction cardiomyopathy, and arrhythmogenic right ventricular dysplasia) were excluded.

\section{Characteristics at implantation}

All variables at ICD implantation were defined and categorized according to the literature or common practice. In addition to age, sex, and New York Heart Association (NYHA) functional status, we recorded the cause of the underlying heart disease (ischemic cardiopathy or dilated cardiomyopathy), level of renal function according to the Cockroft-Gault formula (categorized as creatinine clearance $\geq 60,30-60$, or $<30 \mathrm{ml} / \mathrm{min}$ ), QRS duration, and left ventricular ejection fraction (EF). Atrial fibrillation (AF) was defined as history of AF, documented on electrocardiogram or Holter monitoring. Information on non-sustained ventricular tachycardia recorded on Holter monitoring and electrophysiology testing was collected, and classified as positive or negative. Data on coexisting medical conditions were systematically collected: cancer, chronic obstructive pulmonary disease, chronic renal failure, chronic liver disease, history of transient ischemic attack, and others (including diabetes mellitus).

The type of implanted ICD device (single [VVI] or dual [DDD] chamber, associated or not with cardiac resynchronization therapy [CRT-D], without reference to manufacturing 
companies) was recorded, and device programming was left at the treating physician's discretion. Information on medications at hospital discharge included beta-blockers, amiodarone, class Ic antiarrhythmics, sotalol, digoxin, calcium channel blockers, angiotensinconverting enzyme inhibitors or angiotensin II receptor blockers, diuretics, antiplatelets, and vitamin $\mathrm{K}$ antagonists.

\section{Follow-up and outcomes (including cause-of-death analysis)}

We calculated the incidence of ECs, and assessed patient- and device-related factors that were associated with EC occurrence. The association of ECs with outcomes, including late complications and death, was also evaluated.

ECs were defined as those that appeared during the first 30 days after device implantation, and included lead dislodgement, bleeding or hematoma, sepsis, cardiac tamponade, pneumothorax, and death. Those included peri-operative events but also any significant event, which occurred after hospital discharge within the 30 days after implantation. ICD-related fatal or non-fatal adverse events included infections, lead dislodgement or dysfunction, and inappropriate therapy due to supraventricular tachycardia, lead dysfunction, double counting or noise. Complications that occurred after the first month post-implant were defined as late complications. Follow-up information was obtained from appointments held every 4 to 6 months for device evaluation ${ }^{10}$. Device interrogation printouts were checked by the local investigator for appropriate and inappropriate ICD therapy.

Late complications included inappropriate shock (classified as due to supraventricular tachycardia, lead dislodgement, double counting, and noise), infection, lead dislodgement, lead dysfunction, and ICD-related specific mortality. Vital status was obtained from the hospital or general practitioner, and controlled by the National Institute of Statistics Economical Studies (INSEE). Causes of death were obtained from the investigators or the French Center on Medical Causes of Death (CépiDc-INSERM). Information on causes of death was reviewed by 2 investigators, and classified as sudden death, other cardiovascular 
death, non-cardiovascular death, ICD-related mortality or unknown (when the quality of information did not allow the investigators to appropriately identify the cause). ICD-related mortality was defined as any death due to complication related to the presence of ICD, either during the procedure or afterwards, and classified as early and late, according to the time of occurrence ( $<$ or $>30$ days after ICD implant).

\section{Statistical analysis}

Preparation of this report was in accordance with the Strengthening the Reporting of Observational Studies in Epidemiology (STROBE) statement for reporting of observational studies ${ }^{11}$.

The chi-square test was used for comparison of categorical variables and Student's ttest was used for comparison of continuous variables, where appropriate; Levene's test was used to check the homogeneity of variance; equivalent non-parametric tests were used when Kolmogorov-Smirnov was in favor of absence of normal distribution. Cox regression (forward stepwise method likelihood ratio) was used to identify predictors of mortality and appropriate therapies. The analysis of ECs and mortality were examined through the use of a Cox proportional hazard multivariable regression analysis. Previously, the proportional hazard assumptions were tested. The crude associations between outcomes and different variables were first quantified by univariable Cox regression. All covariates that reached a significance level of $P<20 \%$ were then included in an initial multivariable regression model. A backward stepwise selection was applied to obtain a final model that included covariates with $P<5 \%$.

Predictors were presented with the corresponding odds ratio (OR) and 95\% confidence interval $(\mathrm{Cl})$. Binary logistic regression (forward stepwise method likelihood ratio) was performed to estimate predictors of complications. Kaplan Meier curves were constructed to estimate survivals and compared, using the log-rank test.

Results with $P<0.05$ were considered statistically significant. All data were analyzed at the Paris Cardiovascular Research Centre (INSERM U970, Cardiovascular Epidemiology Unit) using SAS program v9.4 (SAS Institute Inc., Cary, North Carolina). 


\section{Results}

\section{DAI-PP patients}

Among a total of 5539 patients enrolled in DAI-PP, the status of EC occurrence (without/with EC) was known for 5220 (94\%) patients. Baseline characteristics of patients enrolled in DAIPP are shown in Table 1. The mean age was 62.5 years and $84.9 \%$ of patients were male. A total of $3304(60.2 \%)$ patients presented with ischemic cardiopathy and $4489(83.7 \%)$ had an EF $<30 \%$. Approximately one third of patients fell within each of 3 categories of QRS duration ( $<120 \mathrm{~ms}, 120-150 \mathrm{~ms}$, and $>150 \mathrm{~ms})$. A majority $(3916,85.6 \%)$ of patients were in NYHA class II or III, and in sinus rhythm (3589, 76\%). Regarding type of device, 1258 (22.9\%) were implanted with VVI, 1280 (23.3\%) with DDD, and 2952 (53.8\%) with CRT.

Incidence, characteristics, and associated factors of early complications Of 5220 patients with known EC status, 707 (13.5\%) presented with an EC (Table 1). The most frequent complications were bleeding-related (hematoma, 35.9\%) and lead dislodgement (20.7\%) (Figure 1).

Approximately $40.5 \%$ of patients with an EC were on prior anticoagulant treatment versus $34.4 \%$ of patients without EC $(P=.005)$. There were no differences in prior use of antiplatelets.

Patients who had an EC had a more severe cardiac profile than those without complications (Table 1): more EC patients had a QRS $>150 \mathrm{~ms}(P=.002)$, were in NYHA class III $(P=.0002)$, and had renal impairment $(P<.0001)$, and fewer EC patients were in sinus rhythm $(P=.004)$. Of this $13.5 \%$ total EC rate, an $8.65 \%$ was due to CRT patients, $2.75 \%$ to DDD patients, and $2 \%$ to VVI patients. EC occurrence was significantly associated with the type of device ( $64.6 \%$ of patients with EC had a CRT device versus $52.7 \%$ of patients without EC; $P<.0001)$. 
After consideration of potential confounding factors through a multivariable analysis, independent factors associated with the occurrence of EC were severe renal impairment, CRT, prior use of anticoagulant therapy, and age $>=75$ years (Table 2).

\section{Impact of early complications on outcomes}

Follow-up was completed for $93.6 \%$ of patients with known EC status (mean \pm SD follow-up $3.1 \pm 2.3$ years). During follow-up, patients with an EC had earlier battery depletion than patients without EC $(P<.0001)$ (Table 1). A total of $141(19.9 \%)$ patients with an EC died versus $641(14.2 \%, P<.0001)$ of patients without EC. Causes of death were significantly different between the 2 groups, with more sudden deaths and deaths from unknown cause in patients with EC (Table 1).

After multivariable analysis for mortality, ECs were independently associated with a higher risk of overall mortality. NYHA class II-IV, renal impairment, reduced ejection fraction, age $\geq=75$ years, ischemic cardiomyopathy, and AF were also associated with a higher risk of mortality (Table 2). Survival curves for mortality according to the occurrence of early complication are shown in Figure 2.

Data for late complications was complete for 5306 patients. Overall, 824 of 5306 (15.5\%) patients presented with a late complication. Lead dysfunction or dislodgement $(338 / 824,41.0 \%)$ and inappropriate shocks $(286 / 824,34.7 \%)$ were the most common complications. We found no differences in mortality in patients with and without late complications ( 14.9 vs $15.3 \%, P=0.77)$.

After multivariable analysis, late complications were more frequent among patients presenting with an EC (OR 2.15, 95\% $\mathrm{Cl} 1.73-2.66, P<.0001)$.

\section{Discussion}

In this large, multicenter population of patients with ICD for primary prevention in France, we found an EC rate of $13.5 \%$. To our knowledge this is the first study to present a controlled follow-up of complications in a large homogeneous population of patients undergoing primary 
prevention ICD. In this sense, we demonstrated to what extent these ECs are associated with worse outcome, including mortality, during follow-up exceeding 3 years. The negative effect of EC on outcomes has been long suspected ${ }^{6}$, and has been evaluated in a mixed group of primary and secondary prevention patients ${ }^{9}$, but never in such a large real-life primary prevention population.

Few authors have reported rates for EC beyond the hospitalization period. Reported rates vary from $1.8 \%$ to $11 \%$ with a median follow-up of 1 year ${ }^{7,8,12-15}$, with most reports coming from large administrative databases, without specific access to detailed medical records. Among ICD databases, the Implantable Cardioverter-Defibrillator Registry ${ }^{15}$ reported a $3.2 \%$ in-hospital complication rate among patients implanted with an ICD (including replacements and upgrades) for both primary and secondary prevention. In another extensive ICD registry of 104,049 patients, Dewland et al ${ }^{14}$ reported complication rates of $3.17 \%$ in patients receiving de novo double ICDs and $2.11 \%$ in those receiving de novo single chamber ICDs (including use for both primary and secondary prevention). Recently, Dodson et al ${ }^{12}$ reported a lower rate of in-hospital complications of $1.8 \%$ among 240,632 patients, without distinction between use for primary or secondary prevention, and including patients with replacement procedures.

There is, however, a growing sense that complication rates might be higher when evaluated comprehensively ${ }^{6,15}$. Most existing information on procedural complications and their repercussions was extracted from randomized trials, with an expected underestimation of real complication rates, or from large national registries that rely on administrative data. The latter usually underreport complications and comorbid illnesses, and do not reflect the actual clinical situation of implanted patients.

The EC rate of $13.5 \%$ in our study is around 4 -fold higher than that found in registries that rely on administrative data ${ }^{12,14,15}$. Although differences in the definition of EC or patient populations might account for some of the variation across studies, our findings suggest that administrative data may indeed be suboptimal for assessing the real EC rate, and, therefore, their consequences for morbimortality. Data available in North America have relied on large 
administrative databases and claims data, which, while valuable, have some inherent limitations as opposed to direct access to patient medical records and physician-guided adjudication of outcomes, without information on temporal trends for appropriate therapies. Indeed, compared to administrative databases, each case enrolled in the DAI-PP program was "manually" checked and entered in the database, and all outcomes centrally reviewed. The fact that peri-operative complication did not included only those occurring during the index in-hospital stay may explain also the difference.

\section{Factors associated with early complications}

Previous studies have shown that older age, AF, electrical storm, and coexisting conditions are associated with a higher risk of complications following ICD implantation ${ }^{9,12,15,16}$. In our study, older age and severe renal impairment were associated with a higher risk of EC. The number of ICD leads is another factor that has repeatedly been associated with the risk of complications ${ }^{14,17,18}$. Dewland et al ${ }^{14}$ showed in the National Cardiovascular Data Registry ICD Registry population that dual-chamber device implantation was associated with increases in periprocedural complications and in-hospital mortality compared with single-chamber defibrillators. Although the detrimental effects of dual-chamber pacing modes in patients without an indication for pacemaker therapy have been described ${ }^{19}$, in this previous study fewer than half of patients receiving dual-chamber ICDs had such a pacing indication. Furthermore, and consistent with our finding that CRT was independently associated with EC, an OR for complications of 1.7 to 1.8 has been reported for use of a biventricular device ${ }^{12,15}$; both this and an elevated NYHA class were the most important predictors of complications in patients with a de novo ICD implantation. In our population, nearly $70 \%$ of patients had a QRS $>120 \mathrm{~ms}$, and half of them had a QRS $>150 \mathrm{~ms}$. Almost $85 \%$ were in NYHA functional class II-III. In this sense, more than half of our patients were implanted with a CRT-D, and this high rate of complex patients might partially explain our $13.5 \%$ complication rate. 
We found that prior anticoagulant treatment was associated with EC, probably related to hematoma and sepsis. These results are broadly consistent with previous literature ${ }^{9}$, although the effect of anticoagulant therapy in our study was relatively modest (OR of 1.30). Of note, management of anticoagulation therapy was left to the physicians' discretion depending on the hemorrhagic and embolic risks of each patient, and at the time of inclusion, bridging anticoagulation was a frequent practice according to (previous) guidelines ${ }^{20,21}$. An increasing number of centers are now performing ICD implantation without interruption of oral anticoagulation in response to new evidence from trials ${ }^{22,23}$. It would be interesting to evaluate the incidence of EC and overall mortality in the same population with current perioperative anticoagulation practice.

\section{Relation between early complications, late complications, and mortality}

In our study, ECs were associated with significantly higher rates of late complications and mortality over a 3-year follow-up. Lee et al ${ }^{9}$ also described an association between early major complications and mortality, with a hazard ratio of 3.79 in a population of 3340 patients with both primary and secondary prevention implants; this risk was maintained at 180 days.

A plausible hypothesis of the association between ECs and late complications is that the first could trigger the latter: an early hematoma may trigger a subsequent sepsis, and an early lead dislodgement could be related to a particularly difficult right ventricular anatomy resulting from a more complex underlying cardiomyopathy. Early lead dislodgement could also determine an early lead replacement with a subsequent higher risk of infection. In the same way, a more complex cardiac pathology may express itself in a higher risk of mortality.

Especially in primary prevention, optimization of the risk-benefit ratio has relied on identifying mortality-associated factors and, therefore, on improving our selection of patients. As also described in the literature, we found that renal impairment, higher NYHA class, lower EF, and older age are associated with a worse prognosis.

Our results present the relation between ECs and worse outcome in terms of mortality in patients implanted with an ICD in primary prevention. Given that ECs are an 
independent risk factor for mortality, it is evident that we should do our best to prevent them. A result of this is the constant search for new technologies that avoid endovascular access such as subcutaneous ICD's (S-ICD), which to these days show safe results along with a low complication rate. Recently, Burke et al. ${ }^{24}$ reported a $4.5 \%$ EC complication rate and a $11.1 \%$ late complication rate in patients implanted with an S-ICD, with a 3-year estimated mortality rate of $4.2 \%$. However, it is to say that their population differs significantly from ours, with a mean age of 50 years and an EF of $39 \%$ compared to 62 years and $25 \%$, respectively, for our patients. On the other hand, endovascular devices are still the gold standard for defibrillation therapy and the search for improving in this area should continue. In the EC case, prevention could be achieved by a better selection of patients and by better management of patients already presenting an EC risk factor. In our study we identified 2 risk factors (anticoagulation treatment and resynchronization therapy) that predict EC. However, as they are not direct risk factors for mortality, we cannot use them for selecting patients. Nevertheless, they may be useful for identifying a subpopulation that requires more specific care to avoid ECs and to improve mortality outcomes (e.g. by enhancing renal function before implantation, or by better adjustment of anticoagulation treatment).

\section{Study limitations}

Although our data are some of the first to assess the association between EC and outcomes, we acknowledge some limitations. Our study design is retrospective, and does not capture variables such as procedure and fluoroscopy time, or physician or center procedure volume, which have also been reported as predictors of ICD complications ${ }^{13}$.

\section{Conclusion}

In a large multicenter population of primary prevention ICD patients, we observed an EC rate of $13.5 \%$. ECs in this patient population were associated with the occurrence of late complications and with higher mortality. Efforts are therefore needed to prevent ECs by dedicated management of patients before and after ICD implantation. 


\section{CLINICAL PERSPECTIVES}

Implantable cardiac-defibrillators (ICDs) are important for the primary (and secondary) prevention of sudden cardiac death in at-risk patients, but are associated with postimplantation complications. We report the largest analysis to date of the incidence of early complications, and their impact on patient outcomes, in a real-world ICD primary prevention population. Early complications (including bleeding/hematoma and lead dislodgement) occurred in $13.5 \%$ of patients, and were a risk factor for late complications and for mortality during follow-up. Care is therefore needed to minimize the occurrence of complications following ICD implantation, through improved selection of patients, and optimal management of those at increased risk of early complications.

\section{Acknowledgements}

Editorial support on the final version of the paper was provided by MedLink Healthcare Communications Ltd and was funded by the authors. ADREC (Association Dyonisienne de Recherche et Enseignement de Cardiologie) provided secretarial assistance.

Funding: This work was supported by the following independent institutions: the Toulouse Association for the Study of Rhythm Disturbances; the French Institute of Health and Medical Research; and the French Society of Cardiology (NCT 01992458). 


\section{References}

1. Connolly SJ, Gent M, Roberts RS, et al. Canadian Implantable Defibrillator Study (CIDS) A Randomized Trial of the Implantable Cardioverter Defibrillator Against Amiodarone. Circulation. 2000;101(11):1297-1302. doi:10.1161/01.CIR.101.11.1297.

2. Moss AJ, Zareba W, Hall WJ, et al. Prophylactic implantation of a defibrillator in patients with myocardial infarction and reduced ejection fraction. $N$ Engl $J$ Med. 2002;346(12):877-883. doi:10.1056/NEJMoa013474.

3. Kadish A, Dyer A, Daubert JP, et al. Prophylactic defibrillator implantation in patients with nonischemic dilated cardiomyopathy. N Engl J Med. 2004;350(21):2151-2158. doi:10.1056/NEJMoa033088.

4. Bardy GH, Lee KL, Mark DB, et al. Amiodarone or an implantable cardioverterdefibrillator for congestive heart failure. N Engl J Med. 2005;352(3):225-237. doi:10.1056/NEJMoa043399.

5. Ezekowitz JA, Rowe BH, Dryden DM, et al. Systematic review: implantable cardioverter defibrillators for adults with left ventricular systolic dysfunction. Ann Intern Med. 2007;147(4):251-262.

6. Brignole M. Are complications of implantable defibrillators under-estimated and benefits over-estimated? Eur Eur Pacing Arrhythm Card Electrophysiol J Work Groups Card Pacing Arrhythm Card Cell Electrophysiol Eur Soc Cardiol. 2009;11(9):1129-1133. doi:10.1093/europace/eup174.

7. Reynolds MR, Cohen DJ, Kugelmass AD, et al. The frequency and incremental cost of major complications among medicare beneficiaries receiving implantable cardioverterdefibrillators. J Am Coll Cardiol. 2006;47(12):2493-2497. doi:10.1016/j.jacc.2006.02.049. 8. Al-Khatib SM, Lucas FL, Jollis JG, Malenka DJ, Wennberg DE. The relation between patients' outcomes and the volume of cardioverter-defibrillator implantation procedures performed by physicians treating Medicare beneficiaries. J Am Coll Cardiol. 2005;46(8):1536-1540. doi:10.1016/j.jacc.2005.04.063.

9. Lee DS, Krahn AD, Healey JS, et al. Evaluation of early complications related to De Novo cardioverter defibrillator implantation insights from the Ontario ICD database. J Am Coll Cardiol. 2010;55(8):774-782. doi:10.1016/j.jacc.2009.11.029.

10. Chauvin M, Cazeau S, Frank R, et al. [Recommendations from the French Cardiology Society concerning the competence, performance and the environment required for the implantation and surveillance of pacemakers]. Arch Mal Coeur Vaiss. 2006;99(4):275-278. 11. Vandenbroucke JP. The making of STROBE. Epidemiol Camb Mass. 2007;18(6):797799. doi:10.1097/EDE.0b013e318157725d.

12. Dodson JA, Reynolds MR, Bao H, et al. Developing a risk model for in-hospital adverse events following implantable cardioverter-defibrillator implantation: a report from the NCDR (National Cardiovascular Data Registry). J Am Coll Cardiol. 2014;63(8):788-796. doi:10.1016/j.jacc.2013.09.079.

13. Freeman JV, Wang Y, Curtis JP, Heidenreich PA, Hlatky MA. Physician procedure volume and complications of cardioverter-defibrillator implantation. Circulation. 2012;125(1):57-64. doi:10.1161/CIRCULATIONAHA.111.046995.

14. Dewland TA, Pellegrini CN, Wang Y, Marcus GM, Keung E, Varosy PD. Dualchamber implantable cardioverter-defibrillator selection is associated with increased complication rates and mortality among patients enrolled in the NCDR implantable cardioverter-defibrillator registry. J Am Coll Cardiol. 2011;58(10):1007-1013. doi:10.1016/j.jacc.2011.04.039.

15. Haines DE, Wang Y, Curtis J. Implantable cardioverter-defibrillator registry risk score models for acute procedural complications or death after implantable cardioverter-defibrillator implantation. Circulation. 2011;123(19):2069-2076.

doi:10.1161/CIRCULATIONAHA.110.959676.

16. Kirkfeldt RE, Johansen JB, Nohr EA, Jørgensen OD, Nielsen JC. Complications after cardiac implantable electronic device implantations: an analysis of a complete, nationwide cohort in Denmark. Eur Heart J. 2014;35(18):1186-1194. doi:10.1093/eurheartj/eht511. 
17. Duray GZ, Schmitt J, Cicek-Hartvig S, Hohnloser SH, Israel CW. Complications leading to surgical revision in implantable cardioverter defibrillator patients: comparison of patients with single-chamber, dual-chamber, and biventricular devices. Eur Eur Pacing Arrhythm Card Electrophysiol J Work Groups Card Pacing Arrhythm Card Cell Electrophysiol Eur Soc Cardiol. 2009;11(3):297-302. doi:10.1093/europace/eun322.

18. Peterson PN, Varosy PD, Heidenreich PA, et al. Association of single- vs dualchamber ICDs with mortality, readmissions, and complications among patients receiving an ICD for primary prevention. JAMA. 2013;309(19):2025-2034. doi:10.1001/jama.2013.4982. 19. Wilkoff BL, Cook JR, Epstein AE, et al. Dual-chamber pacing or ventricular backup pacing in patients with an implantable defibrillator: the Dual Chamber and VVI Implantable Defibrillator (DAVID) Trial. JAMA. 2002;288(24):3115-3123.

20. Douketis JD, Spyropoulos AC, Spencer FA, et al. Perioperative management of antithrombotic therapy: Antithrombotic Therapy and Prevention of Thrombosis, 9th ed: American College of Chest Physicians Evidence-Based Clinical Practice Guidelines. Chest. 2012;141(2 Suppl):e326S - 50S. doi:10.1378/chest.11-2298.

21. Haute Autorité de Santé. [Good management practices for oral anticoagulant overdose, situations of hemorrhagic risk and hemorrhagic events in patients taking oral anticoagulants in the ambulatory and hospital setting--April 2008]. J Mal Vasc. 2008;33(45):202-213.

22. Ghanbari $\mathrm{H}$, Feldman $\mathrm{D}$, Schmidt $\mathrm{M}$, et al. Cardiac resynchronization therapy device implantation in patients with therapeutic international normalized ratios. Pacing Clin Electrophysiol PACE. 2010;33(4):400-406. doi:10.1111/j.1540-8159.2010.02703.x. 23. Birnie DH, Healey JS, Wells GA, et al. Pacemaker or defibrillator surgery without interruption of anticoagulation. N Engl J Med. 2013;368(22):2084-2093.

doi:10.1056/NEJMoa1302946.

24. Burke MC, Gold MR, Knight BP, et al. Safety and Efficacy of the Totally Subcutaneous Implantable Defibrillator: 2-Year Results From a Pooled Analysis of the IDE Study and EFFORTLESS Registry. J Am Coll Cardiol. 2015;65(16):1605-1615. doi:10.1016/j.jacc.2015.02.047. 
Figure 1. Types of early complications $(n=707)$.

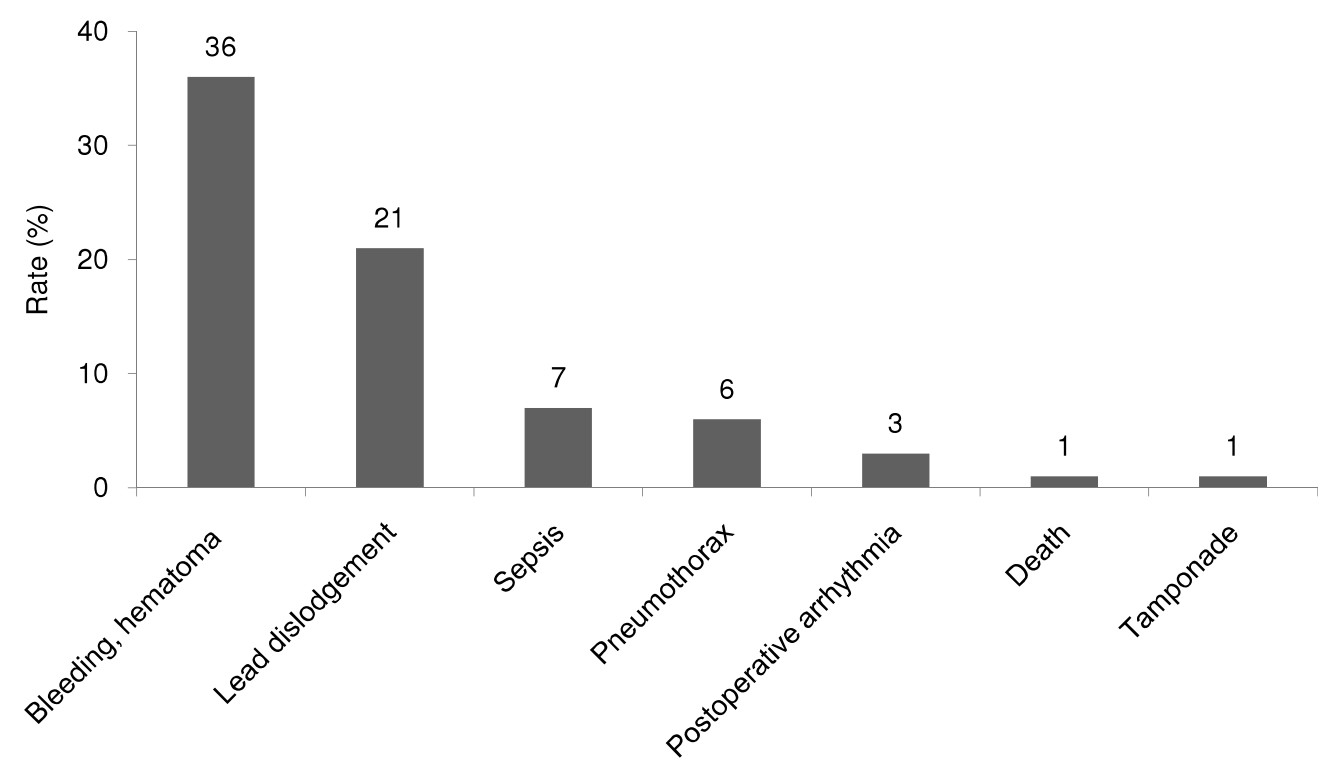

Figure 2. Survival curves for mortality according to the occurrence of early complication.

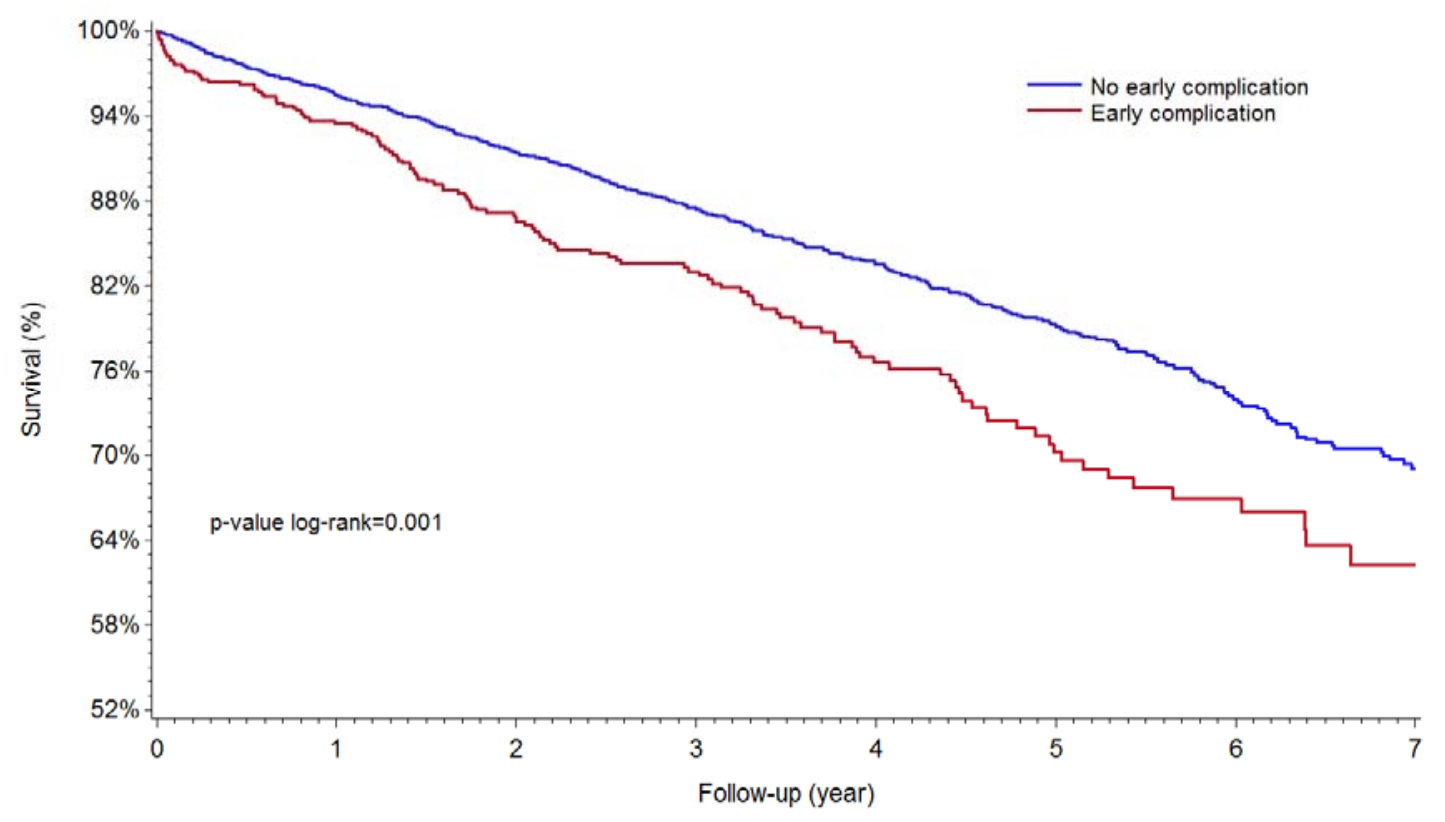


Table 1. Characteristics and outcomes associated with early complications.

\begin{tabular}{|c|c|c|c|c|}
\hline Variable & $\begin{array}{c}\text { All } \\
\text { patients } \\
\mathrm{N}=5539\end{array}$ & $\begin{array}{c}\text { No early } \\
\text { complication } \\
\mathrm{N}=4513\end{array}$ & $\begin{array}{c}\text { Early } \\
\text { complication } \\
\mathrm{N}=707\end{array}$ & $P$-value \\
\hline Age, years $(\mathrm{SD})[\mathrm{N}=5215]$ & $62.5(11.2)$ & $62.2(11.2)$ & $64.5(10.8)$ & $<.0001$ \\
\hline Men, n (\%) & $4729(84.9)$ & $3826(84.8)$ & $597(84.4)$ & .82 \\
\hline \multicolumn{5}{|l|}{ Cardiopathy, n (\%) [N=5173] } \\
\hline $\begin{array}{l}\text { Ischemic } \\
\text { Dilated }\end{array}$ & $\begin{array}{l}3304(60.2) \\
2181(39.8)\end{array}$ & $\begin{array}{l}2697(60.2) \\
1781(39.8)\end{array}$ & $\begin{array}{r}413(59.4) \\
282(40.6)\end{array}$ & .69 \\
\hline \multicolumn{5}{|l|}{$\begin{array}{l}\text { Left ventricular ejection fraction, \%, } n(\%) \\
{[N=5118]}\end{array}$} \\
\hline$<30 \%$ & $4489(83.7)$ & $3728(84.0)$ & $563(82.7)$ & \multirow{3}{*}{.49} \\
\hline $30-45 \%$ & $792(14.8)$ & $639(14.4)$ & $109(16.0)$ & \\
\hline$>45 \%$ & $81(1.5)$ & $70(1.6)$ & $9(1.3)$ & \\
\hline Median ejection fraction, \% (IQR) [N=5118] & $25(22-30)$ & $25.00(22.0 ; 30.0)$ & $27.00(23.0 ; 30.0)$ & .07 \\
\hline \multicolumn{5}{|l|}{ QRS, n (\%) [N=3734] } \\
\hline$<120 \mathrm{~ms}$ & $1183(30.5)$ & $1000(31.5)$ & $138(24.9)$ & \multirow{3}{*}{.002} \\
\hline $120-150 \mathrm{~ms}$ & $1368(35.3)$ & $1125(35.4)$ & $197(35.6)$ & \\
\hline$>150 \mathrm{~ms}$ & $1322(34.1)$ & $1055(33.2)$ & $219(39.5)$ & \\
\hline \multicolumn{5}{|l|}{ NYHA class, $n(\%)[\mathrm{N}=4392]$} \\
\hline$\sqrt{20}$ & $482(10.6)$ & $424(11.3)$ & $47(7.5)$ & \multirow{4}{*}{.0002} \\
\hline II & $1853(40.6)$ & $1546(41.1)$ & $226(36.1)$ & \\
\hline III & $2052(45.0)$ & $1659(44.1)$ & $320(51.1)$ & \\
\hline IV & $175(3.8)$ & $137(3.6)$ & $33(5.3)$ & \\
\hline \multicolumn{5}{|l|}{ Creatinine clearance, $\mathrm{n}(\%)[\mathrm{N}=3150]$} \\
\hline$<30 \mathrm{ml} / \mathrm{min}$ & $280(8.7)$ & $212(7.8)$ & $58(13.6)$ & \multirow{3}{*}{$<.0001$} \\
\hline $30-60 \mathrm{ml} / \mathrm{min}$ & $1001(30.9)$ & $836(30.7)$ & $146(34.1)$ & \\
\hline$>60 \mathrm{ml} / \mathrm{min}$ & $1957(60.4)$ & $1674(61.5)$ & $224(52.3)$ & \\
\hline
\end{tabular}




\begin{tabular}{|c|c|c|c|c|}
\hline Sinus rhythm, $\mathrm{n}(\%)[\mathrm{N}=4529]$ & $3589(76.0)$ & $3003(77.2)$ & $462(72.1)$ & .004 \\
\hline \multicolumn{5}{|l|}{ Number of coexisting conditions [ $\mathrm{N}=3945]$} \\
\hline 0 & $1173(28.0)$ & $930(27.7)$ & $154(26.2)$ & \multirow{4}{*}{.37} \\
\hline 1 & $2339(55.9)$ & $1900(56.6)$ & $326(55.4)$ & \\
\hline 2 & $526(12.6)$ & $410(12.2)$ & $86(14.6)$ & \\
\hline$\geq 3$ & $147(3.5)$ & $116(3.5)$ & $23(3.9)$ & \\
\hline \multicolumn{5}{|l|}{ Type of device, $n(\%)[N=5203]$} \\
\hline CRT & $2952(53.8)$ & $2373(52.7)$ & $453(64.6)$ & \multirow{3}{*}{$<.0001$} \\
\hline DDD & $1280(23.3)$ & $1046(23.2)$ & $144(20.5)$ & \\
\hline VVI & $1258(22.9)$ & $1083(24.1)$ & $104(14.8)$ & \\
\hline \multicolumn{5}{|l|}{ Prior treatment } \\
\hline Anticoagulants (VKA) & $1404(35.28)$ & $1126(34.4 \%)$ & $238(40.5)$ & $<.005$ \\
\hline Antiplatelets & $2278(57.2)$ & $1859(56.8 \%)$ & $351(59.7)$ & .19 \\
\hline \multicolumn{5}{|l|}{ Outcomes } \\
\hline Battery replacement, $\mathrm{n}(\%)[\mathrm{N}=4930]$ & $1023(19.54)$ & $723(17.0)$ & $171(25.2)$ & $<.0001$ \\
\hline $\begin{array}{l}\text { Mean time to battery replacement, } \\
\text { years (SD) }[\mathrm{N}=870]\end{array}$ & $3.87(1.91)$ & $4.1(1.8)$ & $2.8(2.0)$ & $<.0001$ \\
\hline Transplant, n (\%) [N=5132] & $176(3.24)$ & $149(3.4)$ & $12(1.7)$ & .023 \\
\hline Death, $n(\%)[N=5132]$ & $826(15.22)$ & $641(14.2)$ & $141(20.2)$ & $<.0001$ \\
\hline Cause of death & & & & .006 \\
\hline Other cardiovascular & $407(49.27)$ & $325(50.7)$ & $61(43.3)$ & \\
\hline Non-cardiovascular & $197(23.85)$ & $162(25.3)$ & $25(17.7)$ & \\
\hline Sudden & $64(7.75)$ & $46(7.2)$ & $16(11.4)$ & \\
\hline Unknown cause & $144(17.43)$ & $99(15.4)$ & $34(24.1)$ & \\
\hline
\end{tabular}

CRT = cardiac resynchronization therapy; EF = ejection fraction; IQR, interquartile range;

NYHA = New York Heart Association; SD = standard deviation 
Table 2. Multivariable analysis for early complications and overall mortality.

\begin{tabular}{|c|c|c|c|}
\hline Characteristic & $\begin{array}{l}\text { Odds } \\
\text { ratio }\end{array}$ & $\begin{array}{l}\text { 95\% confidence } \\
\text { interval }\end{array}$ & $P$-value \\
\hline \multicolumn{4}{|l|}{ Early complication } \\
\hline $\begin{array}{l}\text { Severe renal impairment (creatinine } \\
\text { clearance }<30 \mathrm{ml} / \mathrm{min} \text { ) }\end{array}$ & 1.66 & $1.17-2.37$ & .02 \\
\hline Cardiac resynchronization therapy & 1.58 & $1.16-2.17$ & .01 \\
\hline Prior use of anticoagulant therapy & 1.30 & $1.02-1.61$ & .03 \\
\hline Age $>=75$ years & 1.01 & $1.00-1.02$ & .03 \\
\hline \multicolumn{4}{|l|}{ Mortality } \\
\hline NYHA class II-V & 1.76 & $1.41-2.16$ & $<.0001$ \\
\hline Creatinine clearance $<30 \mathrm{ml} / \mathrm{min}$ & 1.77 & $1.43-2.16$ & $<.0001$ \\
\hline Ejection fraction $\leq 30 \%$ & 1.69 & $1.38-2.07$ & $<.0001$ \\
\hline Age $\geq 75$ years & 1.02 & $1.00-1.03$ & .002 \\
\hline Ischemic cardiomyopathy & 1.29 & $1.05-1.57$ & .01 \\
\hline Atrial fibrillation & 1.33 & $1.09-1.63$ & .006 \\
\hline Early complication & 1.70 & $1.34-2.17$ & $<.0001$ \\
\hline
\end{tabular}

NYHA $=$ New York Heart Association 